\title{
Molecular and Physiological Responses to Juvenile Traumatic Brain Injury: Focus on Growth and Metabolism
}

\author{
Talin Babikian ${ }^{a}$ e Mayumi L. Prins ${ }^{b, e}$ Yan Cai ${ }^{b, e}$ Garni Barkhoudarian ${ }^{\text {b, e }}$ \\ Ivet Hartonian ${ }^{d, f}$ David A. Hovda ${ }^{b, c, e}$ Christopher C. Giza ${ }^{b, d-f}$ \\ Departments of a Psychiatry, ${ }^{b}$ Neurosurgery, ${ }^{c}$ Molecular and Medical Pharmacology and d Pediatrics, and

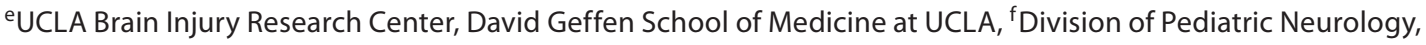 \\ Mattel Children's Hospital UCLA, Los Angeles, Calif., USA
}

\section{Key Words}

Growth $\cdot$ Metabolism $\cdot$ Traumatic brain injury,

experimental $\cdot$ Traumatic brain injury, juvenile $\cdot$ Oxidative stress $\cdot$ Gene expression $\cdot$ Growth factor

\begin{abstract}
Traumatic brain injury (TBI), one of the most frequent causes of neurologic and neurobehavioral morbidity in the pediatric population, can result in lifelong challenges not only for patients, but also for their families. Survivors of a brain injury experienced during childhood - when the brain is undergoing a period of rapid development - frequently experience unique challenges as the consequences of their injuries are overlaid on normal developmental changes. Experimental studies have significantly advanced our understanding of the mechanisms and underlying molecular underpinnings of the injury response and recovery process following a TBI in the developing brain. In this paper, normal and TBI-related alterations in growth, development and metabolism are comprehensively reviewed in the postweanling/juvenile age range in the rat (postnatal days 21-60). As part of this review, TBI-related changes in gene expression are presented, with a focus on the injury-induced alterations related to cerebral growth and metabolism, and discussed in the context of existing literature related to physiological and behav-
\end{abstract}

ioral responses to experimental TBI. Increasing evidence from the existing literature and from our own gene microarray data indicates that molecular responses related to growth, development and metabolism may play a particularly important role in the injury response and the recovery trajectory following developmental TBI. While gene expression analysis shows many of these changes occur at the level of transcription, a comprehensive review of other studies suggests that the control of metabolic substrates may preferentially be regulated through changes in transporters and enzymatic activity. The interrelation between cellular metabolism and activity-dependent neuroplasticity shows great promise as an area for future study for an optimal translation of experimental data to clinical TBI, with the ultimate goal of guiding therapeutic interventions.

Copyright $\odot 2010$ S. Karger AG, Basel

\section{Introduction}

Traumatic brain injury (TBI) is the single most common cause of morbidity in the pediatric population and frequently results in lasting neurobehavioral deficits, which can cause lifelong challenges. Survivors of TBI incurred during a period of rapid brain development in childhood may experience ongoing neurocognitive im-

\section{KARGER}

Fax +41613061234

E-Mail karger@karger.ch

www.karger.com (c) 2010 S. Karger AG, Basel

$0378-5866 / 10 / 0326-0431 \$ 26.00 / 0$

Accessible online at:

www.karger.com/dne
Christopher C. Giza, MD

Department of Neurosurgery, Semel Institute, UCLA Brain Injury Research Center 10833 Le Conte Boulevard, Room 18-218B

Los Angeles, CA 90095 (USA)

Tel. +1 310825 3550, Fax +1 310794 2147, E-Mail cgiza@mednet.ucla.edu 
pairments and exhibit delays in their rate of development relative to healthy peers. Over time, this can result in increasing discrepancies in abilities relative to their healthy age-matched cohort [1], a phenomenon referred to as 'growing into the lesion'. In contrast to injury in adulthood, TBI in the developing brain has distinct consequences with regard to injury response, physiological measures, markers of injury, medication effects, efficacy of therapies and recovery of function $[2,3]$.

Experimental TBI studies in the developing brain have advanced our mechanistic understanding of both the injury response and the recovery process. From this work, the underlying molecular underpinnings of TBI-related developmental plasticity, such as altered neurotransmission, cell death and perturbations in neuronal connectivity, have begun to be characterized [4]. However, this rodent work has been predominantly restricted to the preweanling and weanling rodent (postnatal days 7-20, or P7-20) [4-7]. In this review, normal and TBI-related alterations in growth, development and metabolism will be reviewed in the postweanling/juvenile age range (P21-60). As part of this review, post-TBI gene expression changes will be presented, focusing on the injury-induced expression of genes related to cerebral growth and metabolism. These alterations will be discussed in the context of existing literature related to physiological and behavioral responses to experimental TBI in the juvenile age range rodent.

\section{Developmental Considerations}

\section{Normal Brain Growth}

Neural development across species can be broadly categorized as either activity independent or dependent. The former are 'hardwired' processes that are governed primarily by genetic programming, although potentially adaptable by cellular activity. They include proliferation, neuronal migration, cellular differentiation and apoptosis [8]. Following these programmed processes, activitydependent neurodevelopment helps shape neural/axonal connections by modifying or eliminating established connections through synaptogenesis, axonal sprouting/ growth, myelination and synaptic pruning.

The rat is a particularly good model for the study of normal brain maturation and consequences of disruption to this process since, unlike many other mammals, most of the brain development occurs postnatally [9], although the rate of cerebral maturation is very rapid. Further, metabolic functions in normal circumstances and following a brain insult in the rat resemble those of the developing hu- man brain [10]. In rats, cellular proliferation and migration occur between gestational day 9.5 (G9.5) and P15 [11]. Apoptosis and axonal pruning are thought to follow this period. Using diffusion tensor images, significant reductions in axial diffusivity in the direction of fibers have been reported between P8 and P28, suggesting shortening of axonal lengths during pruning [12]. In contrast, both myelination and synaptogenesis, increasing axonal integrity and connections, result in increases in fractional anisotropy. Myelination in the rat brain begins at approximately $\mathrm{P} 10$, reaching its peak at $\mathrm{P} 20$ and declining in rate through P45, with little gradual change thereafter [13]. Synaptogenesis in the rat brain occurs between P10 and P30 [11], and is followed by a period of pruning. Figure 1 summarizes the stages of normal brain development in the rat.

\section{Ontogeny of Cerebral Metabolism}

Glucose Metabolism

The documented age-related changes in metabolism include the developing brain's shift in its primary fuel source from glucose in utero, to lactate shortly after birth, to a combination of ketones and glucose during suckling (P1-20), and finally to reliance on glucose as the primary energy source after weaning [10]. During the first 1-3 months of life in the developing rat, cerebral glucose utilization increases by about $20 \%$, then declines between 3 and 12 months (despite a lack of decline in cerebral function or regional blood flow) and stabilizes thereafter [14]. As the primary substrate for cerebral metabolism in the normal, uninjured adult brain, glucose is almost entirely oxidized to $\mathrm{CO}_{2}$ and $\mathrm{H}_{2} \mathrm{O}$. In addition to its key role in cerebral metabolism, glucose is also the precursor to various neurotransmitters including $\gamma$-aminobutyric acid, glutamate and acetylcholine [15]. Across species, increases in glucose utilization, and to some extent ketone metabolism, are correlated with cerebral structural and functional maturation $[9,14]$.

Ketone Body Metabolism

In addition to glucose, the brain readily utilizes ketone bodies including acetoacetate and $\beta$-hydroxybutyrate ( $\beta$ $\mathrm{OHB})$. In contrast with the 'slow crescendo' of glucose metabolism in the developing brain, the changes in ketone metabolism are more dramatic [10]. During suckling, circulating ketones increase and the cerebral metabolism of $\beta$-OHB becomes significant. In fact, at the peak of ketone utilization (P15-22), the brain's capacity to use $\beta$-OHB is about 6 times higher than in adults $[16,17]$. Also increasing are the monocarboxylate transporters (MCT), which transport ketones, pyruvate and lactate [10]. 
Fig. 1. Stages of neural development in the

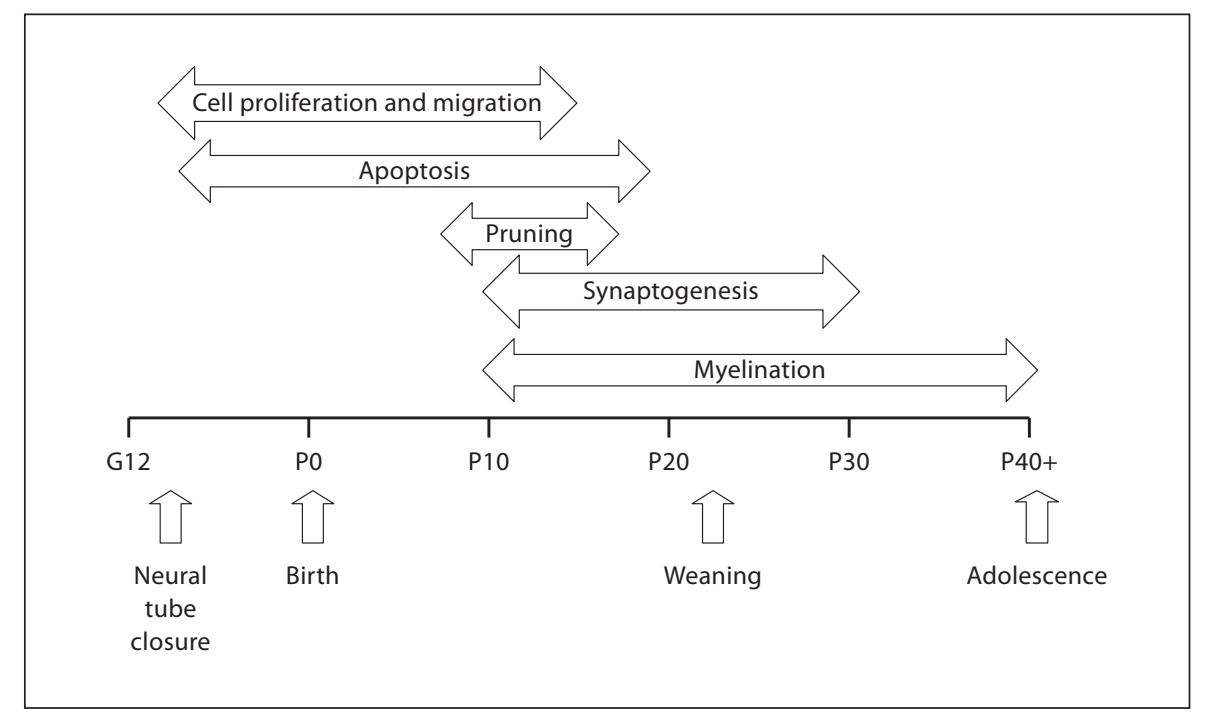

In the adult brain, levels of plasma ketone bodies rise during rapid metabolism of fatty acids by the liver, such as during uncontrolled diabetes and starvation. Metabolism of ketone bodies is generally proportional to their corresponding blood concentration, with the rate-limiting factor being the rate of transport across the bloodbrain barrier $[9,18]$. It is possible to lengthen the period of postnatal ketosis or to shift cerebral metabolism from glucose to ketones by manipulating diets, increasing the uptake of ketones and increasing the enzyme activity needed for ketone metabolism $[10,19]$. However, there is also evidence for 'hardwiring' of changes in cerebral metabolism that is unrelated to the circulating substrate levels [10].

In addition to the age-related dependence on ketone body metabolism, there are age-related regional differences in ketone metabolism. Ketone metabolism is largely homogeneous prior to P35. After this period, the regional pattern of ketone metabolism resembles that of adults, namely pronounced glucose uptake in the cortex (particularly in the 'superficial' layers), while the greatest ketone uptake is observed in the inner cortical layers [20]. Such regional differences suggest that ketone metabolism can supplement but not fully replace glucose metabolism.

In postnatal development, ketone bodies are directly responsible for modulating neuronal excitability by maintaining the cellular membrane resting potential and reversal potential of $\gamma$-aminobutyric-acid-induced anionic currents, with significant depolarization of both potentials evident under conditions of ketone body deficiency [21]. There is increasing evidence that ketone bod- ies have neuroprotective effects that are similar to those of calorie restriction. These effects are related to decreasing reactive oxygen species (ROS) concentrations in mitochondria overloaded with calcium (due in part to upregulation of mitochondrial uncoupling protein) [22] and to increased brain-derived neurotrophic factor (BDNF) activity, most prominently in the hippocampus but also in the basal ganglia [23].

\section{Metabolism and Developmental Plasticity}

Functional neuroimaging such as positron emission tomography has made the noninvasive investigation of metabolism in the developing human brain possible, and shows a phylogenetic order with functional maturation of older anatomic structures preceding that of newer areas [24]. The regional pattern of metabolic increases in the human newborn and later developing infant is consistent in structures that show functional emergence at a given point in time in development $[25,26]$. Further, it has been suggested that at any given developmental age, structures with metabolic rates that are equal to or exceeding the respective levels in the mature brain are those that 'dominate' the behavior at that age [27]. Unlike rodents, measurement of the absolute rates of glucose utilization with positron emission tomography reveals that during the major portion of the first decade, the human brain has a higher energy (glucose) utilization, corresponding to a period of exuberant connectivity and characterized by considerable plasticity in response to injury [28].

Based on the temporal relation between developmental changes and glucose metabolism detected by the local ce- 
rebral metabolic rate of glucose (LCMRglc) in humans and other mammals $[29,30]$, it has been suggested that the ontogenetic changes of glucose metabolism provide an indirect measure of synaptogenesis [28]. There are developmental periods where proliferation/overproduction of neurons and increases in synaptic contact are followed by apoptosis and pruning [24, 31]. These processes are not random, but are experience dependent, with repeated neuronal activity during critical periods resulting in stabilization rather than pruning of these circuits [32]. Some studies implicate $\mathrm{N}$-methyl-D-aspartate (NMDA) receptor activation in this process [33]. Therefore, it seems that the transient maturational changes in LCMRgIc not only predict periods of synaptic excess, but may also indicate when plasticity in the nervous system is at a maximum [28].

\section{Molecular Response to Juvenile TBI}

TBI is a complex, multifaceted process that shares mechanistic elements of excitotoxicity and cerebral ischemia but is unique among types of neural injury because it inherently involves biomechanical forces applied to the brain. When this heterogeneous injury occurs in a developing brain, it is extremely challenging to obtain a comprehensive understanding of the myriad of molecular pathways involved and how they interact to result in cell death, functional impairment and recovery. The use of gene microarrays is one approach to allow a broad overview of the molecular responses in a given experimental system. To the best of our knowledge, this is the first report of this technique in the juvenile rat TBI model.

We used the gene microarray approach to characterize the molecular response profile after lateral fluid percussion injury (FPI) in the postweanling/juvenile rat. P26 rat pups underwent sham, mild or severe lateral FPI $(n=4$ / group) following our standard protocol, using $1.5-2 \%$ isoflurane anesthesia with $100 \%$ oxygen at 2 liters $/ \mathrm{min}$. The craniotomy was placed $3 \mathrm{~mm}$ posterior and $6 \mathrm{~mm}$ lateral to the bregma $[5,34]$. Mild injury was defined as post-FPI toe pinch response of $<45 \mathrm{~s}$ and severe as $>120 \mathrm{~s}$. The loss of toe pinch response represents a neurological postinjury measure of severity that corresponds with atmospheres of pressure applied, duration of apnea and c-fos expression [5]. Rats were sacrificed at 4 and $24 \mathrm{~h}$ after injury, and RNA was isolated from the ipsilateral cortex and hippocampus using standard guanidine thiocyanate extraction [35]. Expression profiling was conducted using Affymetrix rat gene RG U43A arrays. Analysis was performed using the Genesifter software (www.Genesifter.net) with the significance set to detect changes of $>1.8$-fold up- or downregulation compared to sham. One caveat of this approach is that genes with more variable or smaller degrees of expression change may be missed; however, false positives among genes identified as significantly different from sham are minimized. The use of the gene array methodology also has some inherent limitations, primarily related to the semiquantitative nature of the technique. To provide greater certainty that expression changes seen using microarray methods are reflective of quantitative alterations in gene expression, RT-PCR can be conducted on selected genes to validate the microarray results. In previously published work looking at gene expression changes after adult lateral FPI, we have demonstrated good concordance between microarray results and RTPCR [36].

\section{Gene Expression Changes after Juvenile TBI}

Using this system, 352 individual gene sequences showed significant up- or downregulation, 299 of which were identified in the NIH bioinformatics Database for Annotation, Visualization and Integrated Discovery (DAVID; version 6.7; http://david.abcc.ncifcrf.gov/). Once identical genes and redundancies in the data were eliminated, a final 269 individual genes were included in the analyses. Across all of the experimental conditions combined (brain region, time after injury, and severity), individual genes were tabulated more than once if they were represented in more than one of the combinations of experimental conditions above. Overall, there was almost a 4-fold difference in the number of total down- versus upregulated genes ( $\mathrm{n}=111$ and 428 , respectively). To simplify the analyses, gene data across the two time points were collapsed. Of the downregulated genes, 49 were in the mild condition (30 hippocampus and 19 cortex) and 62 were in the severe condition ( 34 hippocampus and 28 cortex). Of the upregulated genes, 187 were in the mild condition (108 hippocampus and 79 cortex) and 241 were in the severe condition (132 in hippocampus and 109 in cortex). See online supplementary table 1 (www. karger.com/doi/10.1159/000320667) for a listing of all the genes and their magnitude of down- and upregulation. The full gene array tables will also be posted online at www.birc.ucla.edu.

While looking at individual genes is of some interest, one of the strengths of the microarray method is to gain an understanding of the overall profile of differentially expressed genes. This is readily done by categorizing genes by their known functions. In recent years, major efforts to standardize the functional classification of genes have re- 
sulted in formal gene ontologies based upon biological process, molecular function and cell localization $[37,38]$. Using the Functional Annotation Table tool of the DAVID, all associated biological process gene ontology terms (GOTERM-BP) were recorded. These terms were used to identify a single primary function and, in many cases, multiple secondary functions for each gene. In the rare instance when a primary function was not readily apparent, the PubMed gene database was searched to identify one. A total of 255 genes were assigned one of 15 primary functions.

Figure 2 shows the overall proportion of down- and upregulated genes, respectively, by their primary function. Across all experimental conditions, genes associated with inflammation/immune processes and cytokine activity were invariably upregulated. In contrast, genes associated with neurotransmission/plasticity, development and, to some degree, metabolism were preferentially downregulated. Figure 3 displays the total number of genes down- and upregulated by experimental conditions. Overall, more of the 15 primary functional categories are represented in the up-versus the downregulated genes. Further, across all conditions, there are slightly more differentially expressed genes in the severe relative to the mild condition within each region. This pattern is particularly striking for the genes associated with cellular metabolism. Interestingly, within the hippocampus, there appear to be a greater number/larger proportion of downregulated genes related to metabolism. Neuroplasticity-related genes seem to show a similar regional pattern, contributing relatively more to the downregulated gene list in the hippocampus. Also of note, approximately half of all genes in each severity condition and region that are downregulated belong to the functional categories associated with growth, development and metabolism (top 5 categories in respective bar graphs). Only about one fourth to, at most, one third of all genes exhibited a similar pattern within upregulated genes.

Comparison with published microarray studies of gene expression after experimental TBI is complicated by differences in injury model, severity, methodology and age $[4,36,39]$. Nonetheless, some general observations may be made as a starting point for further discussion and investigation. As expected, the number of differentially expressed genes generally increased with greater severity of injury. Interestingly, after FPI, P19 pups showed fewer differentially expressed genes than the P26 pups described here, and adult animals showed the greatest number of changed genes. One interpretation is that these observations represent distinct age-related injury responses. However, one must consider whether injury severity as measured by loss of toe pinch is equivalent across ages, and whether greater biological variability may be present in uninjured developing animals as compared to mature shams, both of which may contribute to identifying fewer genes in the younger groups. The pattern of up- versus downregulated genes is also noteworthy as upregulated genes substantially outnumbered downregulated genes at almost every timepoint, severity and age. The notable exceptions were at 4 and $24 \mathrm{~h}$ following moderate FPI in adults, where up- and downregulated genes were approximately equal in number. This suggests that, while injury severity may exist as a continuous spectrum in the immature rat, there appears to be a distinct separation between the molecular responses to moderate and severe FPI in the adult.

Distinctions in the major functional categories of altered genes across age and injury severity may be particularly interesting. Previously, this functional categorization of genes was often conducted manually, making crossstudy comparisons challenging. Future investigations could readily address this concern by comparing altered genes classified by standardized assignment of functional categories using DAVID, as was done in this paper.

\section{Metabolic and Physiological Alterations after Juvenile TBI}

\section{Acute Injury Responses}

TBI in the developing brain is increasingly recognized as having important differences from the adult brain, particularly in terms of injury response (metabolic and molecular) and recovery of function. While dogma suggests that 'younger is better', there is also substantial evidence showing distinct vulnerabilities of the immature brain.

\section{Glucose Uptake}

Alterations in glucose metabolism are a hallmark of TBI across experimental models, and have been observed clinically as well. Immediately after TBI, the adult rat brain shows an indiscriminate efflux of ions and neurotransmitters $[40,41]$ and a transient increase in LCMRglc $[42,43]$ due to increased cellular energy required to restore ionic balance and maintain the neuronal membrane potential [44]. Following the transient increase in LCMRglc is a longer period (10-14 days) of glucose metabolic depression. The duration of this phase of decreased glucose metabolism varies with injury severity, type, and age at injury. The prolonged decrease in LCMRglc after TBI remains unknown, though possible 


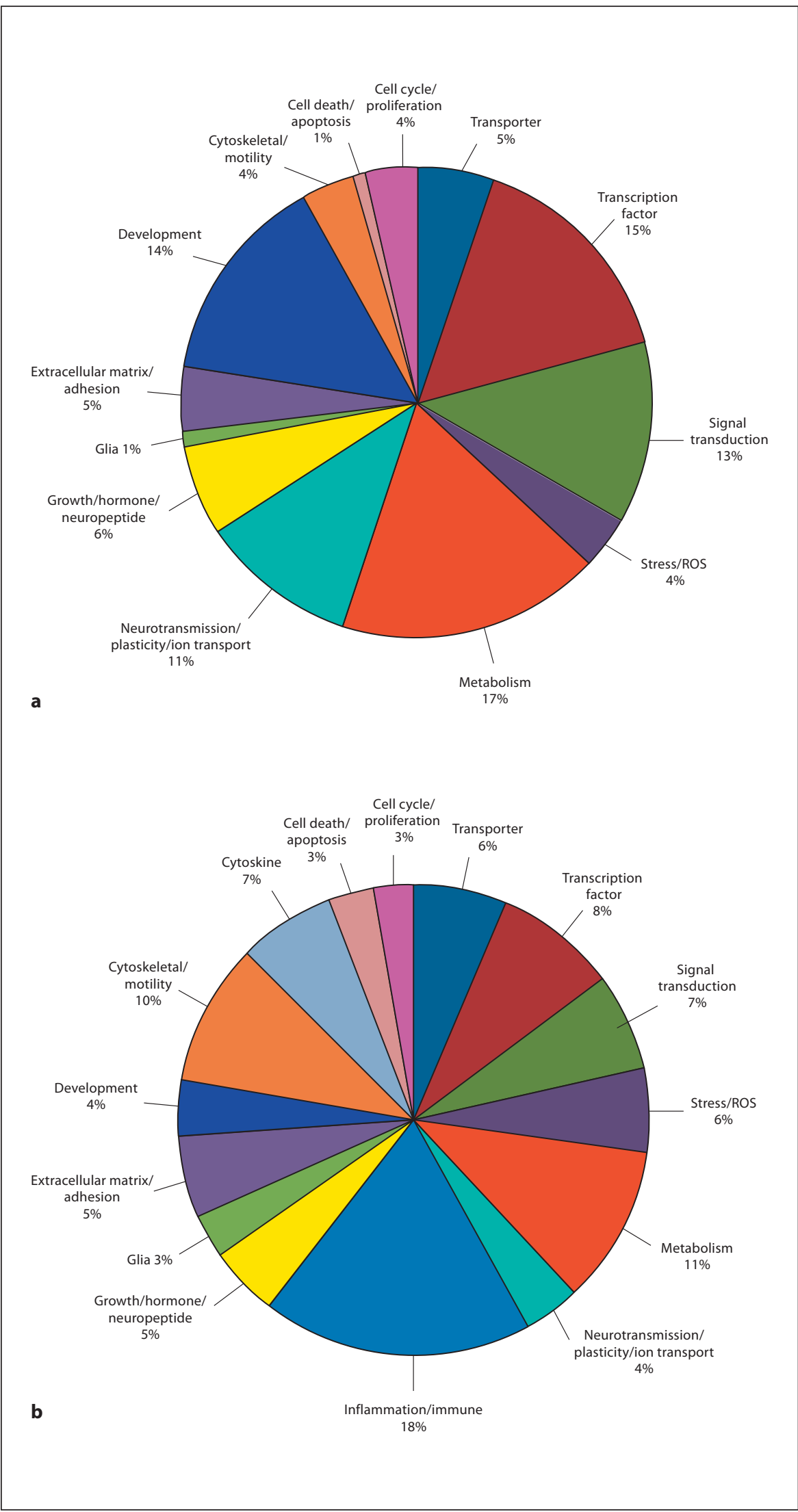

Fig. 2. Proportion of up- and downregulated genes by their primary function. a Downregulated genes $(\mathrm{n}=111)$. b Upregulated genes $(n=428)$. 
Fig. 3. Total number of genes down- and upregulated by assigned primary function for each experimental conditions. a Downregulated genes. b Upregulated genes.

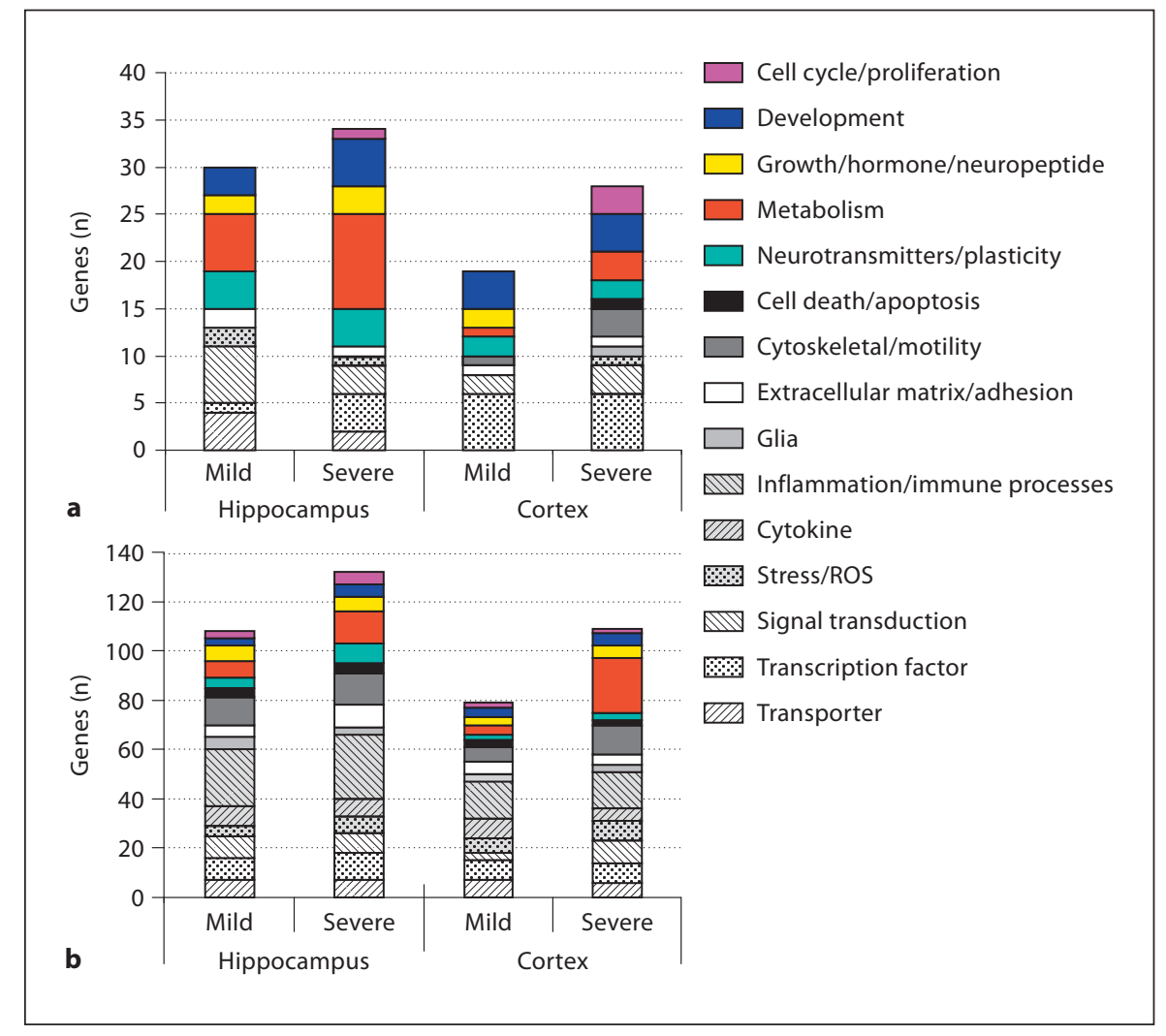

mechanisms include: $\mathrm{Ca}^{++}$-induced mitochondrial disruption [45], ionic flux disruptions [46], reduced cerebral blood flow [47] or lactic acid accumulation [40]. Following the initial surge in neurotransmitter release and ionic fluctuations, brain activity may become quiescent and require less substrate. Several studies have shown a decreased ability of the brain to demonstrate stimulationevoked increases in LCMRglc as early as $4 \mathrm{~h}$ and as long as 2 months after injury [48]. This quiescent state may be a mechanism to reduce secondary injury from premature activation and has also been observed after direct cortical stimulation [49].

While a similar pattern of glucose metabolic alterations occurs after TBI in the P17 rat, the duration of the glucose metabolic depression phase is generally truncated (3 days) relative to adults following FPI [50]. Age-related differences in the duration of LCMRglc depression were also observed among P35 rats after controlled cortical impact injury. In these two injury models with different age groups, the younger brain shows earlier recovery of glucose metabolic rates than adults [51] and suggests age-related differences in metabolic coping strategies or metabolic trafficking.

Molecular and Physiological Responses to Juvenile TBI

\section{Oxidative Stress}

Since free radical production is a normal part of cellular physiology, aerobic organisms have developed various antioxidant defense systems. Enzymatic regulation of free radicals includes superoxide dismutase (SOD), glutathione peroxidase (GPx) and catalases. The expression of these three antioxidant systems changes with cerebral maturation [52, 53]. While catalase and SOD1 $(\mathrm{Cu} /$ ZnSOD, cytoplasmic) activities are generally higher during early development, the primary mitochondrial SOD (MnSOD) demonstrates low activity. During this developmental period, there are age-related differences in endogenous ROS levels. Rat striatal synaptosomes from P7, 12 and 21 all show greater ROS levels than adult synaptosomes [54]. The authors proposed that the higher developmental levels of ROS may be associated with the period of lower mitochondrial antioxidant defense. Following methylmercury application to induce elevated ROS levels, synaptosomes from the younger brains showed greater ROS production than in adults. These results were consistent with the idea that an 'underdeveloped' mitochondrial antioxidant capacity may render the younger brain more vulnerable to oxidative challenges. 
This vulnerability has been experimentally demonstrated after brain injury. While the evidence of oxidative damage following adult brain injury [55-58] has elicited numerous antioxidant treatments to reduce ROS and decrease histopathology [59, 60], little focus has been given to ROS production and consequences of brain injury to the developing brain. GPx activity has been examined in P21 and adult mice after TBI [61]. At $3 \mathrm{~h}$ after injury, P21 mice showed no significant increase in GPx activity, while adults showed a $28 \%$ increase. At $24 \mathrm{~h}$, no significant change was detected among P21 mice, but adults showed a 15\% increase in GPx activity above shams. This lack of inducible GPx enzymatic activity is in contrast to the 1.8-fold increase in hippocampal gene expression at $24 \mathrm{~h}$ after severe injury (online suppl. table 1). Changes in mRNA expression do not necessarily equate to protein levels or protein function. These differences may be reflective of the cell death associated with controlled cortical impact injury, which is not observed following FPI. Collectively, the data from several injury types reveals an increased vulnerability of the younger brain to oxidative challenges due to the lower activities of GPx and MnSOD. The high activities of SOD1 and catalase in the younger animal suggests that cytosolic control of $\mathrm{H}_{2} \mathrm{O}_{2}$ should be efficient despite the low GPx activity. However, the mitochondrial activity of SOD2 is also low and may contribute to hydroxyl radical production and oxidative vulnerability. More data must be acquired to complete our understanding of this vulnerability among different age groups.

\section{Alternative Substrates}

Transporter Changes

Cerebral metabolism of any substrate requires both circulating substrate availability and transport into the brain. Glucose transporter 1 (GLUT1, $55 \mathrm{kDa}$ ) and the MCT1 serve as the primary cerebral endothelial transporters for glucose and ketone bodies, respectively [62, 63], and their expression parallels the developmental switch from a combination of glucose/ketone metabolism in preweanlings to almost exclusive glucose metabolism in the adult brain [64]. The expression of these transporters shows dynamic age-related changes after brain injury. Increases in both GLUT1 and MCT1 protein expression have been shown following hypoglycemia $[65,66]$ and hypoxia/ischemia [67-71]. More recently, our laboratory has shown an increased expression of endothelial MCT2 [72] and MCT1 with a trend toward decreased GLUT1 expression in injured $\mathrm{P} 35$ rats. In contrast, the adult brain showed little change in the expression of MCT1 or GLUT1 within $24 \mathrm{~h}$ after injury [73]. The greater magnitude of MCT1 and
MCT2 expression in the juvenile brain at 6 and $24 \mathrm{~h}$ after injury may contribute to a greater and more rapid ketone uptake during the critical early changes after TBI.

\section{Neuroprotection of Ketone Metabolism after TBI}

Recent studies have shown that glucose processing through glycolysis is altered following TBI. As a consequence of decreases in cytosolic nicotinamide adenine dinucleotide and increased shunting of glucose through the pentose phosphate pathway, glucose metabolism may be an inefficient source of energy in the injured brain. Data from the microarray shows decreases in pyruvate dehydrogenase expression, which would consequently decrease glycolytic activity. Under these conditions, the use of downstream alternative substrates has been shown to be neuroprotective. The developmental difference in the brain's ability to shift toward ketone metabolism may ultimately make the juvenile brain the most receptive to alternative substrates as a therapeutic option after TBI. Recently, conditions of ketosis (induced by fasting or diet) have been shown to be neuroprotective in animal models of TBI in both juvenile and adult rats [74-76]. Administration of ketones after experimental TBI revealed agedependent neuroprotection [77]. P35 and P45 rats placed on the ketogenic diet immediately after controlled cortical impact injury showed a 58 and 39\% decrease, respectively, in cortical contusion volume at 7 days after injury. Both ages also had fewer Fluoro-Jade-positive cells in the cortex and hippocampus $6 \mathrm{~h}$ after injury. The ketogenic (KG) diet had no effect on injured P17 or P75 rats. Administration of ketones after injury not only preserved cortical histology, but also decreased motor and cognitive deficits in the juvenile rats [74]. Motor assessment on the beam walking task revealed longer traverse times for injured P35 animals on the standard and KG diet, but KGfed animals showed fewer footslips than standard-fed animals. P35-injured rats on the KG diet showed shorter escape latencies in the Morris water maze task compared to standard-fed animals. The therapeutic effects of the KG diet on beam walking and cognitive performances were not observed in P75 rats. The fact that there were no changes in expression of genes related to ketone or glucose metabolism (transporters, enzymes) suggests that dynamic changes involved in the regulation of brain metabolism are translationally controlled.

\section{Metabolism and Plasticity}

Metabolism, Learning and Memory

Changes in the brain's metabolic environment can influence cerebral plasticity. Evidence from calorie restric- 
tion, intermittent fasting and exercise has shown a consequent increase in neurotransmitter receptor expression and neurotrophic factors, increased mitochondrial biogenesis $[78,79]$ and increased expression of cellular stress proteins [80]. Intermittent fasting induces the expression of the NMDA receptor subunit NR2B [81], which is the subunit that normally shows declines with aging, concomitant with increased expression of NR2A. Administration of an NR2B subunit antagonist (Ro25-6981) reversed the effects of intermittent fasting. The fact that alterations in caloric intake can alter NMDA receptor subunit composition demonstrates a relationship between substrate metabolism and cellular plasticity.

Increases in neurotrophic factors such as BDNF and ciliary neurotrophic factor have neuroprotective properties and modulate neuronal plasticity. Additionally, BDNF can increase the mitochondrial oxidative efficiency of complex I [82] and has been shown to increase phosphorylation of 5' AMP-activated protein kinase (AMPK) [83], which has been purported to be the 'metabolic biosensor' [84]. AMPK phosphorylation results in activation of efforts to induce energy conservation and appears to decrease long-term potentiation (LTP) [85]. Induction of a state of low cellular energy by 2-deoxyglucose application activates AMPK, which then inhibits LTP. When AMPK activation is inhibited, LTP is restored. Neurotrophins seem to play an important role in cellular energy regulation and plasticity, but this exact relationship is not fully understood.

Studies examining the role of metabolism and plasticity following TBI are sparse. Following FPI in the adult rat, phosphorylated AMPK expression was reduced by $20 \%$ in the ipsilateral hippocampus [86]. Decreases in BDNF after FPI were also observed in P19 [87] and adult rats [88]. Normalization of both AMPK and BDNF have been shown in adults by administration of $\omega-3$ fatty acids [88], exercise [89] or curcumin [90].

\section{Conclusions}

It has long been known that TBI sets off a cascade of metabolic and neuroplastic changes that occur in its wake. Normal cerebral maturation itself involves a complex and interwoven plan that includes substantial alterations in both metabolic pathways and cellular/network plasticity. Increasing evidence indicates that molecular responses related to growth, development and metabolism may play a particularly important role in our understanding of both the acute injury response and the postacute recovery phase when TBI occurs in the immature brain. While gene expression analysis shows many of these changes occur at the level of transcription, other studies indicate that control of metabolic substrates may preferentially be regulated through changes in transporters and enzymatic activity. The interrelation between cellular metabolism and activity-dependent neuroplasticity shows great promise as an area for future study and therapeutic interventions. Understanding the maturation-specific components of this interrelation will be critical to an optimal translation of experimental data to clinical TBI treatments.

\section{Acknowledgments}

This study was supported by the NS27544, NS02197, NS057420, NS058489 and the Child Neurology Foundation/Winokur Family Foundation.

\section{References}

1 Babikian T, Asarnow R: Neurocognitive outcomes and recovery after pediatric TBI: meta-analytic review of the literature. Neuropsychology 2009;23:283-296.

-2 Giza CC, Mink RB, Madikians A: Pediatric traumatic brain injury: not just little adults. Curr Opin Crit Care 2007;13:143-152.

3 Giza CC, Kolb B, Harris NG, Asarnow RF, Prins ML: Hitting a moving target: basic mechanisms of recovery from acquired developmental brain injury. Dev Neurorehabil 2009; 12:255-268.

4 Giza CC, Prins ML: Is being plastic fantastic? Mechanisms of altered plasticity after developmental traumatic brain injury. Dev Neurosci 2006:28:364-379. $\checkmark 5$ Giza CC, Prins ML, Hovda DA, Herschman HR, Feldman JD: Genes preferentially induced by depolarization after concussive brain injury: effects of age and injury severity. J Neurotrauma 2002;19:387-402.

6 Huh JW, Widing AG, Raghupathi R: Midline brain injury in the immature rat induces sustained cognitive deficits, bihemispheric axonal injury and neurodegeneration. Exp Neurol 2008;213:84-92.

7 Jenkins LW, Peters GW, Dixon CE, Zhang X, Clark RS, Skinner JC, Marion DW, Adelson PD, Kochanek PM: Conventional and functional proteomics using large format twodimensional gel electrophoresis 24 hours after controlled cortical impact in postnatal day 17 rats. J Neurotrauma 2002;19:715-740.
8 Spreen O, Risser AH, Edgell D: Developmental Neuropsychology. New York, Oxford University Press, 1995.

9 Miller AL: Brain intermediary metabolism in vivo: changes with carbon dioxide, development, and seizures; in Smythies JR, Bradley RJ (eds): International Review of Neurobiology. New York, Academic Press, 1981, pp 47-82.

10 Prins ML: Cerebral metabolic adaptation and ketone metabolism after brain injury. J Cereb Blood Flow Metab 2008;28:1-16.

11 Rice D, Barone S Jr: Critical periods of vulnerability for the developing nervous system: evidence from humans and animal models. Environ Health Perspect 2000;108(suppl 3):511-533. 
12 Bockhorst KH, Narayana PA, Liu R, Ahobi- 28 Chugani HT: Metabolic imaging: a window la-Vijjula P, Ramu J, Kamel M, Wosik J, Bockhorst T, Hahn K, Hasan KM, Perez-Polo JR: Early postnatal development of rat brain: in vivo diffusion tensor imaging. J Neurosci Res 2008;86:1520-1528.

13 Wiggins R: Myelination: a critical stage in development. Neurotoxicology 1986;7:103-120.

14 Ohata M, Sundaram U, Fredericks WR, London ED, Rapoport SI: Regional cerebral blood flow during development and ageing of the rat brain. Brain 1981;104:319-332.

15 Magistretti PJ, Pellerin L, Martin J: Brain energy metabolism: an integrated cellular perspective; in Bloom FE, Kupfer DJ (eds): Psychopharmacology. The Fourth Generation of Progress. Philadelphia, Lippincott Williams \& Wilkins, 1995, pp 657-670.

16 Hawkins RA, Williamson DH, Krebs HA: Ketone-body utilization by adult and suckling rat brain in vivo. Biochem J 1971;122:13-18.

$\checkmark 17$ Nehlig A, Boyet S, Pereira de Vasconcelos A: Autoradiographic measurement of local cerebral beta-hydroxybutyrate uptake in the rat during postnatal development. Neuroscience 1991;40:871-878.

18 Hawkins RA, Mans AM, Davis DW: Regional ketone body utilization by rat brain in starvation and diabetes. Am J Physiol 1986; 250(pt 1):E169-E178.

$\checkmark 19$ Crane SC, Morgan BL: The effect of alterations in ketone body availability on the utilization of beta-hydroxybutyrate by developing rat brain. J Nutr 1983:113:1063-1072.

-20 Hawkins RA, Biebuyck JF: Ketone bodies are selectively used by individual brain regions. Science 1979;205:325-327.

-21 Rheims S, Holmgren CD, Chazal G, Mulder J, Harkany T, Zilberter T, Zilberter Y: GABA action in immature neocortical neurons directly depends on the availability of ketone bodies. J Neurochem 2009;110:1330-1338.

22 Maalouf M, Rho JM, Mattson MP: The neuroprotective properties of calorie restriction, the ketogenic diet, and ketone bodies. Brain Res Rev 2009;59:293-315.

-23 Duan W, Lee J, Guo Z, Mattson MP: Dietary restriction stimulates BDNF production in the brain and thereby protects neurons against excitotoxic injury. J Mol Neurosci 2001;16:1-12.

24 Chugani HT: A critical period of brain development: studies of cerebral glucose utilization with PET. Prev Med 1998;27:184-188.

$\checkmark 25$ Chugani HT, Phelps ME: Maturational changes in cerebral function in infants determined by ${ }^{18} \mathrm{FDG}$ positron emission tomography. Science 1986;231:840-843.

26 Chugani HT, Phelps ME, Mazziotta JC: Positron emission tomography study of human brain functional development. Ann Neurol 1987;22:487-497.

-27 Kennedy C, Sakurada O, Shinohara M, Miyaoka M: Local cerebral glucose utilization in the newborn macaque monkey. Ann Neurol 1982;12:333-340. on brain development and plasticity. Neuroscientist 1999;5:29-40.

29 Chugani HT, Hovda DA, Villablanca JR, Phelps ME, Xu WF: Metabolic maturation of the brain: a study of local cerebral glucose utilization in the developing cat. J Cereb Blood Flow Metab 1991;11:35-47.

30 Jacobs B, Chugani HT, Allada V, Chen S, Phelps ME, Pollack DB, Raleigh MJ: Developmental changes in brain metabolism in sedated rhesus macaques and vervet monkeys revealed by positron emission tomography. Cereb Cortex 1995;5:222-233.

31 Huttenlocher PR: Synaptic density in human frontal cortex: developmental changes and effects of aging. Brain Res 1979;163:195-205.

32 Rauschecker JP, Marler P: What signals are responsible for synaptic changes in visual cortical plasticity? In Rauschecker J, Marler $P$ (eds): Imprinting and Cortical Plasticity. New York, Wiley, 1987, pp 193-220.

33 Bear MF, Kleinschmidt A, Gu QA, Singer W: Disruption of experience-dependent synaptic modifications in striate cortex by infusion of an NMDA receptor antagonist. J Neurosci 1990;10:909-925.

34 Prins ML, Lee SM, Cheng CL, Becker DP, Hovda DA: Fluid percussion brain injury in the developing and adult rat: a comparative study of mortality, morphology, intracranial pressure and mean arterial blood pressure. Brain Res Dev Brain Res 1996;95:272-282.

35 Chomczynski P, Sacchi N: Single-step method of RNA isolation by acid guanidinium thiocyanate-phenol-chloroform extraction. Anal Biochem 1987;162:156-159.

36 Li HH, Lee SM, Cai Y, Sutton RL, Hovda DA: Differential gene expression in hippocampus following experimental brain trauma reveals distinct features of moderate and severe injuries. J Neurotrauma 2004;21: 1141-1153.

37 Gene Ontology Consortium: The Gene Ontology in 2010: extensions and refinements. Nucleic Acids Res 2010;38(database issue):D331-D335.

38 Lomax J: Get ready to GO! A biologist's guide to the Gene Ontology. Brief Bioinform 2005; 6:298-304.

-39 Matzilevich DA, Rall JM, Moore AN, Grill RJ, Dash PK: High-density microarray analysis of hippocampal gene expression following experimental brain injury. J Neurosci Res 2002;67:646-663.

40 Kawamata T, Katayama Y, Hovda DA, Yoshino A, Becker DP: Administration of excitatory amino acid antagonists via microdialysis attenuates the increase in glucose utilization seen following concussive brain injury. J Cereb Blood Flow Metab 1992;12:12-24.

- 41 Osteen CL, Moore AH, Prins ML, Hovda DA: Age-dependency of ${ }^{45}$ calcium accumulation following lateral fluid percussion: acute and delayed patterns. J Neurotrauma 2001;18:141-162.
42 Sutton RL, Hovda DA, Adelson PD, Benzel EC, Becker DP: Metabolic changes following cortical contusion: relationships to edema and morphological changes. Acta Neurochir Suppl (Wien) 1994;60:446-448.

$\checkmark 43$ Yoshino A, Hovda DA, Kawamata T, Katayama Y, Becker DP: Dynamic changes in local cerebral glucose utilization following cerebral conclusion in rats: evidence of a hyper- and subsequent hypometabolic state. Brain Res 1991;561:106-119.

44 Hovda DA, Villablanca JR, Chugani HT, Phelps ME: Cerebral metabolism following neonatal or adult hemineodecortication in cats. 1. Effects on glucose metabolism using $\left[{ }^{14} \mathrm{C}\right] 2$-deoxy-D-glucose autoradiography. J Cereb Blood Flow Metab 1996;16:134-146.

45 Fineman I, Hovda DA, Smith M, Yoshino A, Becker DP: Concussive brain injury is associated with a prolonged accumulation of calcium: a ${ }^{45} \mathrm{Ca}$ autoradiographic study. Brain Res 1993;624:94-102.

46 Katayama Y, Becker DP, Tamura T, Hovda DA: Massive increases in extracellular potassium and the indiscriminate release of glutamate following concussive brain injury. J Neurosurg 1990;73:889-900.

47 Cherian L, Hlatky R, Robertson CS: Comparison of tetrahydrobiopterin and L-arginine on cerebral blood flow after controlled cortical impact injury in rats. J Neurotrauma 2004;21:1196-1203.

48 Passineau MJ, Zhao W, Busto R, Dietrich WD, Alonso O, Loor JY, Bramlett HM, Ginsberg MD: Chronic metabolic sequelae of traumatic brain injury: prolonged suppression of somatosensory activation. Am J Physiol Heart Circ Physiol 2000;279:H924-H931.

-49 Ip EY, Zanier ER, Moore AH, Lee SM, Hovda DA: Metabolic, neurochemical, and histologic responses to vibrissa motor cortex stimulation after traumatic brain injury. J Cereb Blood Flow Metab 2003;23:900-910.

50 Thomas S, Prins ML, Samii M, Hovda DA: Cerebral metabolic response to traumatic brain injury sustained early in development: a 2-deoxy-D-glucose autoradiographic study. J Neurotrauma 2000;17:649-665.

51 Prins M, Hovda D: The effects of age and ketogenic diet on local cerebral metabolic rates of glucose after controlled cortical impact injury in rats. J Neurotrauma 2009;26:10831093.

52 Mavelli I, Rigo A, Federico R, Ciriolo MR, Rotilio G: Superoxide dismutase, glutathione peroxidase and catalase in developing rat brain. Biochem J 1982;204:535-540.

53 Aspberg A, Tottmar O: Development of antioxidant enzymes in rat brain and in reaggregation culture of fetal brain cells. Brain Res Dev Brain Res 1992;66:55-58.

54 Dreiem A, Gertz CC, Seegal RF: The effects of methylmercury on mitochondrial function and reactive oxygen species formation in rat striatal synaptosomes are age-dependent. Toxicol Sci 2005;87:156-162. 
-55 Tyurin VA, Tyurina YY, Borisenko GG, Sokolova TV, Ritov VB, Quinn PJ, Rose M, Kochanek P, Graham SH, Kagan VE: Oxidative stress following traumatic brain injury in rats: quantitation of biomarkers and detection of free radical intermediates. J Neurochem 2000;75:2178-2189.

56 Singh IN, Sullivan PG, Deng Y, Mbye LH, Hall ED: Time course of post-traumatic mitochondrial oxidative damage and dysfunction in a mouse model of focal traumatic brain injury: implications for neuroprotective therapy. J Cereb Blood Flow Metab 2006; 26:1407-1418.

57 Deng Y, Thompson BM, Gao X, Hall ED: Temporal relationship of peroxynitrite-induced oxidative damage, calpain-mediated cytoskeletal degradation and neurodegeneration after traumatic brain injury. Exp Neurol 2007;205:154-165.

58 Hall ED, Detloff MR, Johnson K, Kupina NC: Peroxynitrite-mediated protein nitration and lipid peroxidation in a mouse model of traumatic brain injury. J Neurotrauma 2004;21:9-20.

59 Mori T, Kawamata T, Katayama Y, Maeda T, Aoyama N, Kikuchi T, Uwahodo Y: Antioxidant, OPC-14117, attenuates edema formation, and subsequent tissue damage following cortical contusion in rats. Acta Neurochir Suppl 1998;71:120-122.

-60 Kawamata T, Katayama Y, Maeda T, Mori T, Aoyama N, Kikuchi T, Uwahodo Y: Antioxidant, OPC-14117, attenuates edema formation and behavioral deficits following cortical contusion in rats. Acta Neurochir Suppl 1997;70:191-193.

-61 Fan P, Yamauchi T, Noble LJ, Ferriero DM: Age-dependent differences in glutathione peroxidase activity after traumatic brain injury. J Neurotrauma 2003;20:437-445.

62 Pardridge WM, Boado RJ, Farrell CR: Braintype glucose transporter (GLUT-1) is selectively localized to the blood-brain barrier: studies with quantitative Western blotting and in situ hybridization. J Biol Chem 1990; 265:18035-18040.

- 63 Gerhart DZ, Enerson BE, Zhdankina OY, Leino RL, Drewes LR: Expression of monocarboxylate transporter MCT1 by brain endothelium and glia in adult and suckling rats. Am J Physiol 1997;273(pt 1):E207-E213.

-64 Vannucci SJ, Simpson IA: Developmental switch in brain nutrient transporter expression in the rat. Am J Physiol Endocrinol Metab 2003;285:E1127-E1134.

-65 Simpson IA, Appel NM, Hokari M, Oki J, Holman GD, Maher F, Koehler-Stec EM, Vannucci SJ, Smith QR: Blood-brain barrier glucose transporter: effects of hypo- and hyperglycemia revisited. J Neurochem 1999;72: 238-247.

66 Sakurai T, Yang B, Takata T, Yokono K: Synaptic adaptation to repeated hypoglycemia depends on the utilization of monocarboxylates in Guinea pig hippocampal slices. Diabetes 2002;51:430-438.
67 Zhang F, Vannucci SJ, Philp NJ, Simpson IA: Monocarboxylate transporter expression in the spontaneous hypertensive rat: effect of stroke. J Neurosci Res 2005;79:139-145.

68 Vannucci SJ, Reinhart R, Maher F, Bondy CA, Lee WH, Vannucci RC, Simpson IA: Alterations in GLUT1 and GLUT3 glucose transporter gene expression following unilateral hypoxia-ischemia in the immature rat brain. Brain Res Dev Brain Res 1998;107: 255-264.

69 Véga C, Sachleben LR Jr, Gozal D, Gozal E: Differential metabolic adaptation to acute and long-term hypoxia in rat primary cortical astrocytes. J Neurochem 2006;97:872883.

70 McCall AL, van Bueren AM, Nipper V, Moholt-Siebert M, Downes H, Lessov N: Forebrain ischemia increases GLUT1 protein in brain microvessels and parenchyma. J Cereb Blood Flow Metab 1996;16:69-76.

71 Urabe T, Hattori N, Nagamatsu S, Sawa H, Mizuno Y: Expression of glucose transporters in rat brain following transient focal ischemic injury. J Neurochem 1996;67:265-271.

72 Prins ML, Giza CC: Induction of monocarboxylate transporter 2 expression and ketone transport following traumatic brain injury in juvenile and adult rats. Dev Neurosci 2006;28:447-456.

73 Deng-Bryant Y, Giza CC, Hovda D, Prins ML: Changes in Vascular MCT1 and GLUT1 transporters following traumatic brain injury. J Neurotrauma, submitted.

74 Appelberg KS, Hovda DA, Prins ML: The effects of a ketogenic diet on behavioral outcome after controlled cortical impact injury in the juvenile and adult rat. J Neurotrauma 2009;26:497-506.

75 Davis LM, Pauly JR, Readnower RD, Rho JM, Sullivan PG: Fasting is neuroprotective following traumatic brain injury. J Neurosci Res 2008;86:1812-1822.

76 Prins ML, Lee SM, Fujima LS, Hovda DA: Increased cerebral uptake and oxidation of exogenous $\beta \mathrm{HB}$ improves ATP following traumatic brain injury in adult rats. J Neurochem 2004;90:666-672.

77 Prins ML, Fujima LS, Hovda DA: Age-dependent reduction of cortical contusion volume by ketones after traumatic brain injury. J Neurosci Res 2005;82:413-420.

78 Anson RM, Guo Z, de Cabo R, Iyun T, Rios M, Hagepanos A, Ingram DK, Lane MA, Mattson MP: Intermittent fasting dissociates beneficial effects of dietary restriction on glucose metabolism and neuronal resistance to injury from calorie intake. Proc Natl Acad Sci USA 2003;100:6216-6220.

79 Fontan-Lozano A, Lopez-Lluch G, DelgadoGarcia JM, Navas P, Carrion AM: Molecular bases of caloric restriction regulation of neuronal synaptic plasticity. Mol Neurobiol 2008;38:167-177.
80 Mattson MP, Duan W, Lee J, Guo Z: Suppression of brain aging and neurodegenerative disorders by dietary restriction and environmental enrichment: molecular mechanisms. Mech Ageing Dev 2001;122:757-778.

-81 Fontan-Lozano A, Saez-Cassanelli JL, Inda MC, de los Santos-Arteaga M, SierraDominguez SA, Lopez-Lluch G, DelgadoGarcia JM, Carrion AM: Caloric restriction increases learning consolidation and facilitates synaptic plasticity through mechanisms dependent on NR2B subunits of the NMDA receptor. J Neurosci 2007;27:1018510195.

82 Markham A, Cameron I, Franklin P, Spedding M: BDNF increases rat brain mitochondrial respiratory coupling at complex I, but not complex II. Eur J Neurosci 2004;20: 1189-1196.

-83 Escartin C, Pierre K, Colin A, Brouillet E, Delzescaux T, Guillermier M, Dhenain M, Deglon N, Hantraye P, Pellerin L, Bonvento G: Activation of astrocytes by CNTF induces metabolic plasticity and increases resistance to metabolic insults. J Neurosci 2007;27: 7094-7104.

84 Ramamurthy S, Ronnett GV: Developing a head for energy sensing: AMP-activated protein kinase as a multifunctional metabolic sensor in the brain. J Physiol 2006;574(pt 1):85-93.

-85 Potter WB, O’Riordan KJ, Barnett D, Osting SM, Wagoner M, Burger C, Roopra A: Metabolic regulation of neuronal plasticity by the energy sensor AMPK. PLoS One 2010; 5:e8996.

86 Wu A, Ying Z, Gomez-Pinilla F: Omega-3 fatty acids supplementation restores mechanisms that maintain brain homeostasis in traumatic brain injury. J Neurotrauma 2007; 24:1587-1595.

87 Griesbach GS, Hovda DA, Molteni R, Gomez-Pinilla F: Alterations in BDNF and synapsin I within the occipital cortex and hippocampus after mild traumatic brain injury in the developing rat: reflections of injuryinduced neuroplasticity. J Neurotrauma 2002;19:803-814.

88 Wu A, Ying Z, Gomez-Pinilla F: Dietary omega-3 fatty acids normalize BDNF levels, reduce oxidative damage, and counteract learning disability after traumatic brain injury in rats. J Neurotrauma 2004;21:14571467.

89 Griesbach GS, Hovda DA, Gomez-Pinilla F: Exercise-induced improvement in cognitive performance after traumatic brain injury in rats is dependent on BDNF activation. Brain Res 2009;1288:105-115.

90 Sharma S, Zhuang Y, Ying Z, Wu A, GomezPinilla F: Dietary curcumin supplementation counteracts reduction in levels of molecules involved in energy homeostasis after brain trauma. Neuroscience 2009; 161:10371044. 